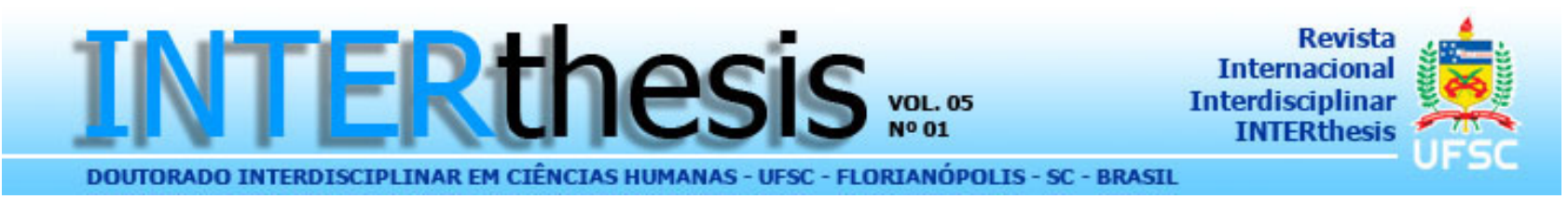

\title{
DE COMO SALVAR A UNIVERSIDADE PÚBLICA DELA MESMA*
}

\author{
ON HOW TO SAVE THE PUBLIC UNIVERSITY FROM ITSELF
}

SOBRE COMO SALVAR LA UNIVERSIDAD PÚBLICA DE ELLA MISMA

\author{
Héctor Ricardo Leis ${ }^{1}$ \\ Selvino Assmann ${ }^{2}$
}

\begin{abstract}
RESUMO
Análise dos entraves da universidade pública contemporânea, em particular, para contribuir ao desenvolvimento do país. Para tal fim se mostra o déficit de diplomados na área das engenharias e o democratismo de sua gestão administrativa. Reivindicam-se o mérito e a excelência acadêmica como fatores principais da reforma necessária na universidade pública.
\end{abstract}

Palavras-chave: Universidade pública; Brasil

\section{ABSTRACT}

This paper is an analysis of the impediments of the contemporary public university, in particular, to contribute to the development of the country. For such end, it is shown the deficit of graduates in the area of engineering and the democratic of its administrative management. Merit and academic excellence are demanded as main factors of the necessary reform in the public university.

Key-words: Public university; Brazil

\section{RESUMEN}

Análisis de los obstáculos de la universidad pública contemporánea, en particular, para contribuir al desarrollo del país. Para tal fin se muestra el déficit de diplomados en el área de las ingeniarías y el democratismo de su gestión administrativa. Se reivindican el mérito

\footnotetext{
$\star$ Uma versão preliminar deste texto foi publicada no jornal mensal Floripa Total, Ano 3, № 25-26, 2007.

1 Doutor em Filosofia pela Pontifícia Universidade Católica do Rio de Janeiro. Professor Associado do Departamento de Sociologia e Ciência Política e docente do Doutorado Interdisciplinar em Ciências Humanas da Universidade Federal de Santa Catarina (UFSC). E-mail: hector.leis@gmail.com
}

2 Doutor em Filosofia pela Pontificia Università Lateranense, PUL, Itália. Professor Titular em Filosofia do Departamento de Filosofia e docente do Doutorado Interdisciplinar em Ciências Humanas da Universidade Federal de Santa Catarina (UFSC). E-mail: selvinoa@terra.com.br

R. Inter. Interdisc. INTERthesis, Florianópolis, v.5, p. 122-130, jan./jul. 2008. 
y la excelencia académica como factores principales de la reforma necesaria en la universidad pública.

Palabras-clave: Universidad pública; Brasil

Enquanto a velha direita se confunde com a nova esquerda na sua defesa da soberania nacional contra supostos avanços de imperialismos démodés, a história continua seu curso indiferente àqueles que se negam a compreendê-la. As principais lutas do século XXI não possuem fronteiras, deixando os ardorosos defensores da soberania, como aconteceu a Dom Quixote, lutando contra moinhos de vento. A riqueza material das nações baseia-se cada vez menos nos recursos naturais. Embora sendo fatores importantes, esses recursos não são mais a principal riqueza de uma nação, tal como foram nas últimas centúrias. No século $X X I$, o conhecimento tornou-se a principal fonte da riqueza. Vivemos na sociedade da informação e do conhecimento, que se nutre da educação do povo em geral e, muito em particular, da produção de idéias de excelência e de tecnologias de ponta. Neste contexto, pode se dizer que, olhando para o estado das escolas e universidades de um país, estaremos olhando para seu futuro.

A abundância de recursos naturais pode constituir-se, muitas vezes, em passaporte para o atraso. O prognóstico do desenvolvimento já não descansa na abundância dos recursos naturais. Apostar em países como a Nigéria, a Arábia Saudita ou a Venezuela, apenas com base na existência de seu abundante petróleo, sem considerar seus outros aspectos culturais e políticos, comportaria uma grande miopia histórica. No início do século XX, dez das doze maiores empresas dos Estados Unidos exploravam e comercializavam recursos naturais, enquanto hoje são apenas duas as que o fazem. Como assinala Andrés Oppenheimer, infelizmente não é esse o caso da América Latina. Aqui as maiores empresas continuam sendo as que trabalham com recursos naturais. As quatro maiores empresas da região são petrolíferas (a nossa Petrobras é uma delas).

O potencial econômico de uma nação não deve ser medido exclusivamente pelas suas reservas de recursos naturais, mas, sobretudo pelos investimentos em educação e no capital cultural e científico disponível. O indicador mais comum para medir esse potencial na área de ciência e tecnologia expressa-se através do número de patentes registradas anualmente. Entre 1977 e 2004, os Estados Unidos registraram, por exemplo, 1.631.000 patentes, contra 538.000 do Japão, 210.000 da Alemanha, 55.000 da Coréia do Sul e só 1.600 de Brasil. Percebe-se que um país pequeno como a Coréia do Sul (99.270

R. Inter. Interdisc. INTERthesis, Florianópolis, v.5, p. 122-130, jan./jul. 2008. 
km2, com cerca de 50 milhões de habitantes) gera uma tremenda renda renovável por direitos de propriedade intelectual, enquanto os países da América Latina precisam atacar ferozmente seus recursos não renováveis para produzir riqueza. Os países que mais investem em educação são, portanto, e obviamente, os que mais produzem patentes e cientistas capacitados. Não surpreendem, portanto, os dados da UNESCO. Segundo esse organismo, os Estados Unidos investem 36\% do total mundial destinado a pesquisa e desenvolvimento, enquanto a União Européia investe 23\% e o Japão 13\%. Mas a importância desses investimentos não deve ser atribuída à circunstância de se tratar de economias poderosas. Nem sempre uma coisa segue a outra: o Brasil, embora estando no seleto clube das dez maiores economias do mundo, nem por isso investe pesado em pesquisa e desenvolvimento. O contrário é mais verdadeiro: são os países que investem pesado em pesquisa e desenvolvimento que se convertem inexoravelmente em economias fortes.

Mas o caso brasileiro é ainda pior, já que o Estado gasta mal. De acordo com estatísticas recentes do IBGE, entre 2001-2006, os gastos com a administração pública corresponderam a $19,9 \%$ do PIB, quase o dobro do que foi gasto entre 1967-86 (10,3\%). Isso quer dizer que o valor consumido hoje no Brasil pelo governo é altíssimo e os brasileiros deveriam receber algo bem melhor do que recebem como serviço público. Essa taxa de quase $20 \%$ do PIB gasta pelo governo para manter sua administração funcionando é muito superior à de outros países também emergentes, que, no entanto, crescem mais rápido e oferecem serviços de melhor qualidade à sua população. Por exemplo, enquanto o Brasil consome 20\%, a Irlanda consome 14,8\%, a Coréia do Sul $12,7 \%$ e o Chile 12,6\%. Quem teve a oportunidade de conhecer os serviços que são oferecidos nesses países não pode deixar de ficar perplexo frente à triste realidade brasileira.

Voltando ao tema da educação, as coisas ficam ainda piores. Apesar do governo brasileiro gastar muito de forma ineficiente, ele também gasta muito pouco em educação quando comparado com a média dos países desenvolvidos e emergentes (como os mencionados acima). Em 2005, o gasto público em educação no Brasil foi de $4,1 \%$ do PIB, enquanto a média desses países foi de 5,4\% (para fundamentar melhor esta comparação, observe-se que a Coréia do Sul, com um governo que gasta apenas 12,7\% do PIB com sua máquina pública, mantém estudando nas suas universidades $89 \%$ de 
seus jovens, enquanto no Brasil, gastando 19,9\%, apenas $20 \%$ dos jovens freqüentam a universidade). O quadro fica mais triste quando se comprova que também se gastam mal esses escassos 4,1\% destinados à educação. Nosso ensino público fundamental e médio é ruim, enquanto nosso ensino superior é razoável.

Chegando mais diretamente ao tema da universidade pública, existe algum outro fator que possa preocupar ainda mais ao leitor e o cidadão brasileiro? Existe, sim. $\mathbf{0}$ ensino superior parece não enxergar corretamente o país real.

Colocando a questão em outros termos: será que nosso ensino superior atende às necessidades de desenvolvimento competitivo no mundo globalizado? Por mais que se possa discutir até que ponto uma universidade deva estar a serviço do mercado de trabalho existente, ou se deve também se preocupar em sugerir mudanças neste mercado, alguns dados podem mostrar que, além dos problemas com a qualidade acadêmica, falta um projeto acadêmico que sintonize as necessidades da nação. Comparemos, por exemplo, o Brasil com a China. Nesse país emergente, apesar de sua população ser numerosa (mais de um bilhão e trezentos milhões de seres humanos, dos quais 200 milhões estão em alguma escola estudando) e em grande medida pobre (a classe média da China é menor que a do Brasil), se criou nos últimos um claro projeto de sociedade, forjando assim um claro projeto educacional. A China gasta 90 bilhões de dólares com educação, 13,3\% do orçamento total do país, enquanto o Brasil investe 21 bilhões de dólares, $1,3 \%$ do orçamento geral. $E$ de saída podemos dizer que a quantidade anual de engenheiros que se formam na China representa uma proporção de 1/3400 de sua população, enquanto a média de Brasil é de 1/7300. Em 2005, com cerca de vinte milhões de estudantes universitários, e graduando anualmente cerca de três milhões e quatrocentos mil jovens, a China formou entre estes cerca de 600.000 novos engenheiros. Contando com a formação tecnológica em outras escolas, a China forma assim anualmente cerca de um milhão de técnicos. Enquanto isso, no Brasil, o total formado anualmente no ensino superior no Brasil é de 620.000 pessoas, mas entre eles estão apenas 94.000 engenheiros por ano, incluindo também as escolas técnicas. Tenhase em conta que, em 2005, mesmo com um crescimento sensível a partir de 1997, havia no cadastro do INEP o registro de 1.251 cursos de engenharia (405 no estado de São Paulo, e só trezentos fora do sul e do sudeste do Brasil). Tenha-se em conta também que a China, por mais que esteja pedindo uma colaboração financeira aos alunos das 
universidades, $66 \%$ das instituições de ensino superior são públicas, enquanto no Brasil menos de um terço ainda é pública. Contudo, mesmo assim, o governo brasileiro gasta doze vezes mais com ensino superior, comparando com o gasto com ensino fundamental, enquanto o governo chinês gasta apenas três vezes mais.

O que nos dizem todos estes dados comparativos entre dois países emergentes?

Obviamente, Brasil produz bem menos engenheiros em termos absolutos que a China, mas o que preocupa no cálculo anterior é que se estão formando aqui poucos engenheiros em proporção à população que existe. Analisando o mesmo problema por outro ângulo se verifica, segundo o MEC, que nas maiores universidades brasileiras mais da metade dos alunos estão matriculados em ciências sociais e humanidades, enquanto apenas $17 \%$ cursam engenharia, física ou matemática. Quatro cursos representam 46,3\% dos alunos universitários brasileiros, cursos de baixo custo: administração $(14,9 \%)$, direito $(12,8 \%)$, pedagogia $(9,3 \%)$, letras $(4,7 \%)$ e comunicação $(4,6 \%)$, enquanto todas as engenharias alcançam 5,9\% dos alunos. Se há no censo feito pelo MEC em 2005620.000 alunos de administração, há apenas 247.000 alunos de todas as engenharias, e cerca de 35.000 alunos em química, ou física, ou agronomia, e apenas 124 alunos em recursos pesqueiros. Algo parecido ocorre na pós-graduação: em 2005, o Brasil formou 1.114 doutores em engenharias (são 139 cursos de doutorado na área), num total de quase nove mil novos doutores. No resto dos países de América Latina não é diferente. Na Universidade de Buenos Aires, a maior universidade da Argentina, se formam anualmente 5 vezes mais psicólogos que engenheiros, por exemplo. Na América latina, por conta da ideologização do sistema universitário, se está criando uma oferta progressivamente exagerada de vagas para cursos que passam muito longe do mercado de trabalho e das verdadeiras necessidades de desenvolvimento do país.

Além de se ter no Brasil um dado preocupante, pois se há apenas $7,7 \%$ da população com formação universitária (na Austrália, mais de 40\% tem curso universitário), praticamente a metade dos alunos que ingressam em cursos universitários não se forma (no Japão, apenas 7\% deixa de se formar - um pouco maior do que o índice de $4 \%$ de alunos de medicina que no Brasil não concluem o curso), sabe-se pelo IBGE (Censo de 2000) que $53 \%$ dos formados exercem profissão diferente daquela para a qual se formou, o que torna problemático o ensino profissionalizante brasileiro.

R. Inter. Interdisc. INTERthesis, Florianópolis, v.5, p. 123-131, jan./jul. 2008. 
Nesse contexto Brasil apresenta uma perversão extra. Enquanto nos países da região a maioria dos alunos que ingressa no ensino superior público, fez seu ensino médio também em escolas públicas, no Brasil é o contrário. Aqui, $85 \%$ dos alunos de ensino médio estudam em escolas públicas e apenas 15\% em escolas particulares pagas. Desse grupo dos $85 \%$, em função da baixa qualidade do ensino recebido, aqueles que quiserem fazer ensino superior dificilmente podem aspirar a ingressar na universidade pública e estão na sua maioria condenados a trabalhar para pagar uma universidade privada. Os alunos de escolas particulares, bem mais ricos que os das públicas, apesar de representar apenas o $15 \%$ do total, irão ocupar quase o $60 \%$ das vagas das universidades públicas. Em outras palavras, no Brasil, a chance de um aluno rico poder ingressar em universidade publica e gratuita é 8 vezes maior que a de um aluno pobre. Será que esta anomalia não estará também associada à falta de opções para que os alunos de origem pobre possam seguir carreiras em ciência e tecnologia, como engenharias e outras?

O primeiro paradoxo da perversidade do sistema de ensino brasileiro se constata no fato das universidades ofertarem um número proporcionalmente baixo de vagas para as carreiras que o desenvolvimento do país precisa. O segundo paradoxo da perversidade do sistema de ensino brasileiro, não menos triste que o primeiro, é que os alunos pobres, por estudarem em escolas de ensino médio ruins, sejam praticamente obrigados a pagar universidades privadas, também ruins, que ofertam cursos que pouco atendem às necessidades de desenvolvimento do país (em função desses cursos serem geralmente mais caros e complexos de ministrar e portanto menos lucrativos para as instituições). Como se desata esse nó gordiano, partindo da própria universidade?

Pedir o simples aumento do orçamento das universidades públicas (reivindicação constante desde os reitores até os sindicatos de docentes e de servidores técnicosadministrativos, e até mesmo dos centros de estudantes) não significa necessariamente construir o futuro. A falta de atenção para a realidade social e econômica do país, torna à universidade publica brasileira em produtora de um quantum considerável de injustiça social e de desempregados qualificados. Reclamar pelo orçamento da universidade publica ou pelos salários dos professores no atual contexto (apesar da justiça de seus reclamos destes, sobretudo quando comparados com outros funcionários de menor qualificação e maiores rendimentos de outras áreas da administração pública), parece ser 
mais um recurso para encobrir a inércia acadêmica das autoridades, assim como uma expressão de certo cinismo e/ou ingenuidade por parte dos professores.

No entanto, sair dessa encruzilhada não é nada fácil. A universidade pública gerou fortes entraves para inviabilizar qualquer reforma que não seja em beneficio do status quo. O principal desses entraves é o democratismo crescente que a perpassa. Os atores das universidades públicas desenvolveram uma concepção corporativa do principio da autonomia. O art. 207 da Constituição de 1988 estabelece que "As universidades gozam de autonomia didático-científica, administrativa e de gestão financeira e patrimonial...". Mas também no art. 206 estabelece, entre outros princípios, que o ensino será ministrado com base na: "igualdade de condições para o acesso e permanência na escola;... gratuidade do ensino público em estabelecimentos oficiais;... gestão democrática do ensino público, na forma da lei."

Não se trata de negar nenhum desses princípios, mas de compatibilizá-los em função dos interesses da nação como um todo. A autonomia foi outorgada historicamente às universidades para preservá-las dos avanços do Estado, em função de interesses conjunturais dos grupos governantes, contra o necessário exercício da liberdade acadêmica dos professores. Mas no Brasil, embora essa liberdade esteja sendo preservada, nos últimos anos a autonomia não tem servido para a universidade operar as necessárias reformas e ajustes periódicos de sua proposta de ensino e pesquisa. A universidade pública ficou presa na rede de interesses corporativos que se amparam no suposto exercício democrática de sua gestão para defender as posições adquiridas dos que já estão dentro, obturando uma representação mais universal que inclua os interesses dos que estão de fora (não apenas dos alunos potenciais, mas do povo em geral, que espera que a universidade atenda ao desenvolvimento do país, gerando uma maciça oferta de vagas na área de ciência e tecnologia).

Por que as universidades públicas brasileiras, por exemplo, não redistribuem seus recursos e esforços para multiplicar por 10 as vagas de seus colégios de aplicação de ensino médio e fundamental, zelando por que estes voltem a ser de excelência como já foram no passado? Desta forma poderiam entrar péla porta grande do vestibular os alunos pobres que tenham suficiente mérito. Mas não, a autonomia tem servido nos últimos anos para quase esquecer a existência dos colégios de aplicação, tornando assim necessário pensar em sistema de cotas para o ingresso à universidade pública, que 
acabarão resultando num aviltamento ainda maior da qualidade do ensino atual. Por que as universidades públicas não tem realizado reformas tendentes a aumentar a proporção de vagas em cursos curtos de vocação interdisciplinar em áreas científico-técnicas? Mas não, a autonomia tem servido para os docentes se entrincheirarem nas defesas dos cursos tradicionais de seus departamentos e centros, em contra dos interesses dos alunos pobres que ficam de fora.

O democratismo tem permitido a utilização do conceito constitucional da "gestão democrática do ensino público, na forma da lei” para fins corporativos. Na maioria das universidades federais, por exemplo, na hora de escolher reitores ou diretores de centro se produz um curioso esquecimento da parte que diz "na forma da lei", para introduzir uma representação corporativa que desqualifica a essência da instituição universitária. Parece não importar á ninguém que a forma da lei estabelece que o $70 \%$ do peso da eleição do reitor descansa no voto dos professores. Na hora da eleição, o democratismo exige que a representação seja tripartite entre professores, alunos e servidores técnicoadministrativos, ou mesmo por voto universal (de acordo com a fórmula "um homem, um voto"), onde todos se igualam, dando assim a chance absurda que o peso dos alunos calouros seja expressivamente maior que a de todo o corpo docente.

A democracia é um regime político de virtudes inocultáveis. É o melhor regime possível para os cidadãos escolherem seus governantes. Mas as regras que se aplicam à forma de governo de uma nação devem aplicar-se às restantes instituições da sociedade? O democratismo se traduz, precisamente, na intenção de levar para as restantes instituições da sociedade o que vale para a escolha dos representantes políticos. Quando se pretende democratizar a família, por exemplo, se está querendo dizer que a "autoridade" deverá surgir da maioria (geralmente dos filhos), contra a minoria dos pais? Ser democrático implica também, por acaso, que na empresa mandem os empregados e nas forças armadas os soldados? A aplicação universal do princípio da democracia a todas as instancias da sociedade antes que aprofundar a mesma levaria a anarquia à sociedade como um todo. Levaria ao esgotamento das forças da nação através da tomada de decisões por parte daqueles menos preparados para tomá-las (nas famílias, os filhos; nas escolas e universidades, os alunos; etc.).

Mas isto é precisamente o que parecem querer alguns dos que levantam a bandeira da autonomia, impedindo que a universidade opere as reformas que a sociedade 
precisa. É impossível não concordar com Mariano Grondona quando observa que o democratismo nas escolas e universidades levaria aos professores ficarem reféns dos piores alunos. Por esse caminho, os melhores professores passariam ser aqueles que dão melhores notas e exigem menos dos alunos. O democratismo acabaria com a universidade porque colocaria os interesses corporativos por cima dos acadêmicos. $\mathrm{Na}$ universidade, cada integrante vale de acordo com seus méritos no campo do conhecimento. No lugar onde se deve premiar o esforço e o rendimento não pode reger a democracia senão a meritocracia. Todos os jovens que ingressam na universidade devem desfrutar de igualdade de oportunidades. A rigor, esse é o sentido íntimo da gratuidade da escola pública. Sendo esta gratuita, todos têm a mesma igualdade de oportunidades para desenvolver suas potencialidades. Mas aqueles que desenvolvem melhor suas capacidades não poderiam nunca ser igualados com aqueles que as desenvolvem menos, a risco de produzir senão uma desmoralização completa da vida acadêmica.

A universidade deveria ser mais democrática na hora de dar maiores chances aos alunos pobres para fazer um ensino médio de qualidade, a partir de políticas que a levem, por exemplo, a ter melhores e maiores colégios de aplicação. Do mesmo modo, a universidade deveria ser mais democrática na hora de ofertar as vagas para seus cursos, aumentado sensivelmente a proporção de vagas para cursos na área de ciência e tecnologia. No entanto, se a universidade quer cumprir sua função deverá privilegiar o principio meritocrático, tanto no seu vestibular, como na provisão de fundos para pesquisa, nas notas das disciplinas, nos concursos dos professores ou nas escolhas de suas autoridades. Evitando o democratismo, a universidade estaria se salvando dos fatores entrópicos que a perseguem. Estaria abrindo o caminho para as reformas que a sociedade precisa. A excelência e o reconhecimento do mérito são as portas para o futuro na época da sociedade da informação e do conhecimento. Se o democratismo nos faz esquecer nossas responsabilidades, a história, essa deusa impiedosa e meritocrática, haverá de passar a conta a nossos filhos e netos.

R. Inter. Interdisc. INTERthesis, Florianópolis, v.5, p. 123-131, jan./jul. 2008. 